\title{
Albumin-to-alkaline phosphatase ratio as a promising indicator of prognosis in human cancers: is it possible?
}

Lin $A n^{1}$, Wei-tian Yin ${ }^{1}$ and Da-wei Sun ${ }^{2 *}$ (D)

\begin{abstract}
Background: The impact of albumin-to-alkaline phosphatase ratio (AAPR) on prognosis in cancer patients remains uncertain, despite having multiple relevant studies in publication.

Methods: We systemically compiled literatures from 3 databases (Cochrane Library, PubMed, and Web of Science) updated to May 24th, 2020. Hazard ratios (HRs) and 95\% confidence intervals (Cls) were computed and synthesized using STATA 14, values were then pooled and utilized in order to assess the overall impact of AAPR on patient's prognosis.

Results: In total, 18 studies involving 25 cohorts with 7019 cases were incorporated. Pooled results originated from both univariate and multivariate analyses ( $H R=2.14,95 \% \mathrm{Cl}: 1.83-2.51$, random-effects model; $H R=1.93,95 \% \mathrm{Cl:1.75-}$ 2.12, fixed-effects model; respectively) suggested that decreased AAPR had adverse effect on overall survival (OS). Similarly, pooled results from both univariate and multivariate analysis of fixed-effects model, evinced that decreased AAPR also had adverse effect on disease-free survival (DFS) (HR=1.81,95\%Cl:1.60-2.04, $P^{2}=29.5 \%, P=$ $0.174 ; H R=1.69,95 \% \mathrm{Cl}: 1.45-1.97, P^{2}=13.0 \%, P=0.330$; respectively), progression-free survival (PFS) $(H R=1.71,95 \% \mathrm{Cl}$ : $1.31-2.22, P=0.0 \%, P=0.754 ; H R=1.90,95 \%(1: 1.16-3.12, P=0.0 \%, P=0.339$; respectively), and cancer-specific survival (CSS) $\left(H R=2.22,95 \% \mathrm{Cl}: 1.67-2.95, P^{2}=5.6 \%, P=0.347 ; H R=1.88,95 \% \mathrm{Cl}: 1.38-2.57, P^{2}=26.4 \%, P=0.244\right.$; respectively). Admittedly, heterogeneity and publication bias existed, but stratification of univariate meta-analytic results, as well as adjusted meta-analytic results via trim and fill method, all showed that AAPR still significantly correlated with poor OS despite of confounding factors.
\end{abstract}

Conclusions: In summary, decreased AAPR had adverse effect on prognosis in cancer patients. As an inexpensive and convenient ratio derived from liver function test, AAPR might become a promising indicator of prognosis in human cancers.

Keywords: Albumin-to-alkaline phosphatase ratio (AAPR), Cancers, Prognosis, Meta-analysis

\footnotetext{
* Correspondence: sundawei2008@sina.cn

${ }^{2}$ Department of Hepatobiliary and Pancreatic Surgery, The First Hospital of Jilin University, Changchun 130021, Jilin, China

Full list of author information is available at the end of the article
}

C C The Author(s). 2021 Open Access This article is licensed under a Creative Commons Attribution 4.0 International License, which permits use, sharing, adaptation, distribution and reproduction in any medium or format, as long as you give appropriate credit to the original author(s) and the source, provide a link to the Creative Commons licence, and indicate if changes were made. The images or other third party material in this article are included in the article's Creative Commons licence, unless indicated otherwise in a credit line to the material. If material is not included in the article's Creative Commons licence and your intended use is not permitted by statutory regulation or exceeds the permitted use, you will need to obtain permission directly from the copyright holder. To view a copy of this licence, visit http://creativecommons.org/licenses/by/4.0/ The Creative Commons Public Domain Dedication waiver (http://creativecommons.org/publicdomain/zero/1.0/) applies to the data made available in this article, unless otherwise stated in a credit line to the data. 


\section{Background}

Cancer is a major public health problem worldwide and is the second leading cause of death in the United States [1]. According to GLOBOCAN 2018, an estimated 18.1 million new cancer cases and 9.6 million cancer deaths happened worldwide [2]. Due to the growing and aging population as well as advances in diagnosis and therapy, cancer survivors number continues to increase [3]. So far, the prognostic markers for cancer survivors are diverse, but most of them except clinical-pathological factors, are not used in our clinical work due to high cost or inconvenience. Therefore, seeking practical markers to assess patients' prognosis before the administration of treatment is urgently needed, so that therapeutic modality could be individually tailored, or augmented for an improved outcome [4].

Liver function test (LFT) is an universally used laboratory test to assess liver function in clinical work. Serving as an indicator of LFT, albumin is the most abundant protein in human plasma, and its concentration reflects the protein status of the blood and function of internal organs. Meanwhile, albumin is also a valuable biomarker of diverse diseases, including both malignant tumors and benign diseases (liver diseases, inflammation, malnutrition, and diabetes mellitus, etc.) [5, 6]. Alkaline phosphatase (ALP) is another important indicator of LFT, whose elevation is universally recognized as a marker of hepatobiliary or skeletal diseases [7]. Besides, the elevation of ALP was also reported to be found in diverse malignancies (osteosarcoma, testicular neoplasm, prostate cancer, pancreatic cancer, breast cancer, and ovarian cancer, etc.), and its elevation was usually correlated with poor outcomes [8]. Interestingly, as a combined ratio index derived from LFT, albumin to alkaline phosphatase ratio (AAPR) was firstly investigated to be a novel index of prognosis in hepatocellular carcinoma (HCC) patients in 2015 [9]. Henceforth, a series of studies have tried to explore the use of AAPR as a marker of prognosis in human cancers [10-26].

However, results from these emerging findings are inconsistent. For instance, some of them evinced that elevated AAPR was associated with poor survival outcomes $[9,10,12-21,23-26]$, but others evinced that elevated AAPR was not correlated with survival outcomes [11, 22]. Additionally, qualities of the above mentioned studies are variable, especially in terms of cancer types and methodology. Therefore, this meta-analysis was conducted to determine whether AAPR can serve as a novel indicator of prognosis in human cancers.

\section{Methods}

This meta-analysis was conducted in accordance with Preferred Reporting Items for Systemic Reviews and Meta-analysis (PRISMA) issued in 2009 [27].

\section{Literatures research}

We systemically sought relevant literatures in 3 databases (Cochrane Library, PubMed, and Web of Science). The search strategies were "albumin-to-alkaline phosphatase ratio in All Text OR albumin to alkaline phosphatase ratio in All Text OR AAPR in All Text" used in Cochrane Library, "(( (albumin-to-alkaline phosphatase ratio) $O R A A P R)$ OR albumin to alkaline phosphatase ratio OR Albumin/alkaline Phosphatase Ratio)" used in PubMed, TS = ("albumin-to-alkaline phosphatase ratio" $O R$ "AAPR" OR "albumin to alkaline phosphatase ratio" OR "Albumin/alkaline Phosphatase Ratio") used in Web of Science. The searching time without starting time updated to May 24th, 2020. During the process of full-text reading, the references of retrieved literatures were further manually browsed to find underlying literature.

\section{Criteria for literature selection}

In this process, we selected the literatures based on three major criteria. First, the clinical study investigated the prognostic determinant role of AAPR regardless of human cancer type. Secondly, the survival endpoints of mentioned cancers are required to be well documented, including overall survival (OS), recurrence-free survival (RFS), disease-free survival (DFS), progression-free survival (PFS) and/or cancer-specific survival (CSS). Lastly, the hazard ratios (HRs) of the study endpoints should either be original or be calculated by utilizing the data, tables or graphs provided in the literature. We discarded case reports, review articles and comment letters. In situations where multiple literature used data from the same population sources, we preferred the literature with the maximum amount of cases.

\section{Data extraction and quality assessment}

Two authors (AL and SDW) generated a compiled table, including the following contents: 1st author, year of publication, cancer site, sample size, study duration, design approach, cutoff value of AAPR, number of cases in each group, treatment strategy, survival outcome, HR data, analytic method (univariate/multivariate), HR source and follow-up interval. If the HR was not raw, the software Engauge Digitizer 4.1 was used to read the KaplanMeier curve to estimate the number of deaths/recurrences/survivors. Then, HR with its 95\% CI was estimated by following practical methods (incorporating summary time-to event data into meta-analysis) created by Tierney et al. [28]. The authors extracted the contents of the table individually, and then exchanged their results. In this meta-analysis, Newcastle-Ottawa Scale (NOS) score was utilized to assess the included literature quality [29]. During this process, any discrepancies of opinion were resolved by reaching consensus through meetings held by participating authors. 


\section{Statistic analysis}

Software STATA 14 was utilized for data analysis in this research. HRs and 95\% CIs were combined to evaluate the overall impact of AAPR on prognosis, including OS, DFS, PFS and CSS. If the lower limit of pooled 95\% CIs was greater than 1 , the decreased AAPR was considered to have an adverse effect on prognosis. Heterogeneity across included studies was examined by Chi-square test and $I^{2}$, and the significance was set at either or both of $P<0.1$ and $I^{2}>50 \%$. In case of both $I^{2}<50 \%$ and $P \geq$ 0.1 , we used a fixed-effects model to compute the pooled HRs. Otherwise, the random-effects model was adopted to perform data analysis. In addition, we assessed publication bias by following Begg's and Egger's methods [30, 31]. We followed a trim and fill method to further testify the stability of pooled results, when cases of publication bias were found [32]. Across this research, a $P$ value that is less than 0.05 was deemed as significant. In this research, we followed the methodology of statistic analysis, which was also used in our previously published research [33].

\section{Results}

\section{Summary of systemic literature search}

As shown in Fig. 1 by following the PRISMA flow chart [27], 18 studies with 25 cohorts were incorporated in our meta-analysis finally [9-26]. The publishing year for these studies ranged from 2015 to 2020, with the total number of cancer cases of 7019, all of which were based in Asian countries (16 from China's mainland, the other two from Korea and Hong Kong). In terms of cancer sites, 5 studies reported lung cancer (LC), 4 studies reported HCC, 3 studies reported nasopharyngeal carcinoma, and the other 6 studies reported cervical cancer, cholangiocarcinoma, breast cancer, renal cell cancer, upper tract urothelial carcinoma, pancreatic duct adenocarcinoma, respectively. All other basic information relevant to these studies are displayed in Table 1. Following the NOS criteria, all of the included studies achieved the score $\geq 6$, with the score ranging from 6 to 8 (Supplementary table).

\section{Meta-analysis with OS}

Regarding OS, 17 studies involving 20 cohorts with 5921 cases by univariate analytic results and 15 studies involving 20 cohorts with 6156 cases by multivariate analytic results were collected in total. It showed that the decreased AAPR had an adverse effect on OS in patients with cancers, which is not only taken from pooled univariate analytic results $(H R=2.14,95 \% C I: 1.83-2.51, P \leq$ $0.001)$ of random-effects model $\left(I^{2}=62.2 \%, p \leq 0.001\right)$ [Fig. 2a], but also from pooled multivariate analytic results $(H R=1.93,95 \% C I: 1.75-2.12, \quad P \leq 0.001)$ of the fixed-effects model $\left(I^{2}=0.0 \%, p=0.496\right)$ [Fig. $\left.2 \mathrm{~b}\right]$.

\section{Meta-analysis with DFS}

There were a total of nine studies involving 10 cohorts with 3014 cases and six studies involving 7 cohorts with 2584 cases separately investigating the impact of AAPR on DFS via univariate and multivariate analysis. Heterogeneity existed in neither of these two pooled metaanalyses $\left(I^{2}=29.5 \%, p=0.174 ; I^{2}=13.0 \%, p=0.330\right.$; respectively), revealing that decreased AAPR also had adverse effect on DFS $(H R=1.81,95 \% C I: 1.60-2.04, P \leq$ $0.001 ; H R=1.69,95 \%$ CI:1.45-1.97, $P \leq 0.001$; respectively) by the fixed-effects model [Fig. 3a-b].

\section{Meta-analysis with PFS and CSS}

On the whole, two studies with 331 cases and two studies with 309 cases was separately used to evaluate the impact of AAPR on PFS by univariate and multivariate analysis, respectively. The pooled meta-analysis results of the fixed-effects model $\left(I^{2}=0.0 \%, p=0.754 ; I^{2}=\right.$ $0.0 \%, p=0.339$; respectively) supported that decreased AAPR also corelated with poor PFS $(H R=1.71,95 \% C I$ : $1.31-2.22, \quad P \leq 0.001 ; \quad H R=1.90,95 \%$ CI:1.16-3.12, $P \leq$ 0.001) [Fig. 4a]. Similarly, two studies with 3 cohorts involving 1315 cases and two studies involving 1111 cases investigated the impact of AAPR on CSS via univariate and multivariate analysis, individually. According to the pooled results of the fixed-effects model $\left(I^{2}=5.6 \%, p=\right.$ $0.347 ; I^{2}=26.4 \%, \quad p=0.244 ;$ respectively), decreased AAPR also correlated with poor CSS $(H R=2.22,95 \% C I$ : 1.67-2.95, $P \leq 0.001 ; \quad H R=1.88,95 \% C I: 1.38-2.57, \quad P \leq$ 0.001) [Fig. 4b].

\section{Stratification for OS from univariate analysis}

Heterogeneity existed across the included studies reporting OS via univariate analysis, thus, stratified metaanalysis was performed. These stratification were performed according to year of publication, cancer site, sample size, study design, treatment strategy, AAPR cutoff value, HR source and follow-up interval. Overall, it was found that the correlation between AAPR and OS remains stable despite the fluctuations of these variables, which was summarized in Table 2.

\section{Publication bias}

Publication bias did not exist in meta-analysis with DFS via either univariate or multivariate analytic results $(P=$ $0.721, P=0.382 ; P=0.548, P=0.148$; respectively), which was examined by following both Begg's and Egger's methods. But, publication bias existed in the metaanalysis with $O S$ via both univariate and multivariate analytic results $(P=0.021, P=0.001 ; P=0.018, P=0.020$; respectively). Upon further investigation of the adjusted meta-analysis results by following the trim and fill method, AAPR is still significantly correlated with poor OS [Fig. 5a-b]. 


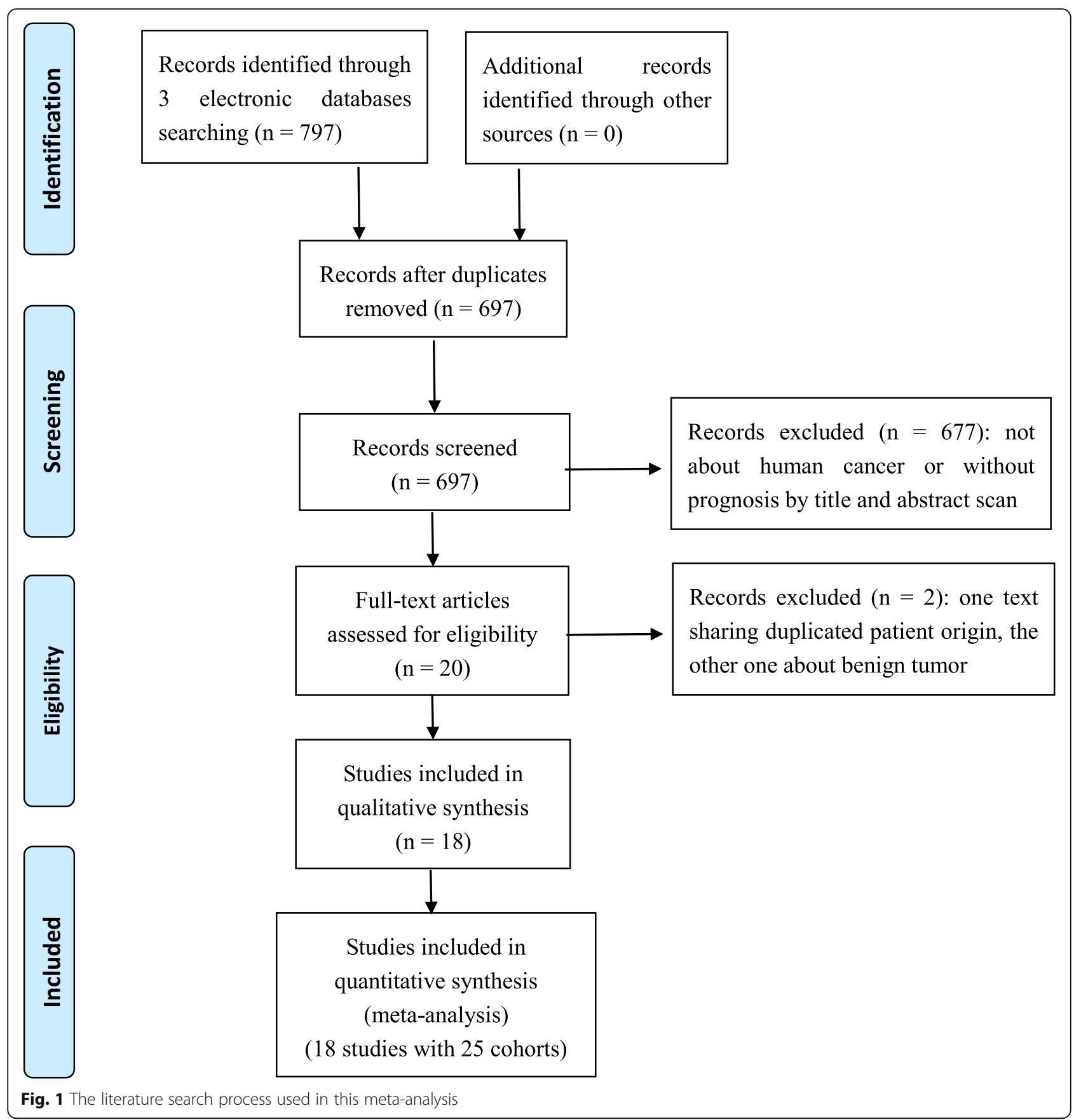

\section{Sensitivity analysis}

After omitting any individual study, we did not observe overall fluctuation of combined HRs for OS (Fig. 6a-b), DFS (Fig. 6c-d), PFS and CSS (Fig. 6e-f). Namely, the pooled HRs results from our meta-analysis were relatively robust.

\section{Discussion}

It has been 5 years since the first reported study revealed that AAPR was a novel index of prognosis in patients with HCC [9]. In the years following, AAPR has been investigated to evaluate survival outcomes in diverse human cancers [10-26]. However, the association between AAPR and prognosis in patients with cancers has not been illustrated by evidence-based medicine yet. In this current research, we initially evaluated the prognostic role of AAPR in patients with cancers through metaanalysis. From the perspective of evidence-based medicine, our pooled meta-analysis results presented that decreased AAPR had adverse effects on OS, DFS, PFS and 
An et al. BMC Cancer $\quad$ (2021) 21:247

Page 5 of 18

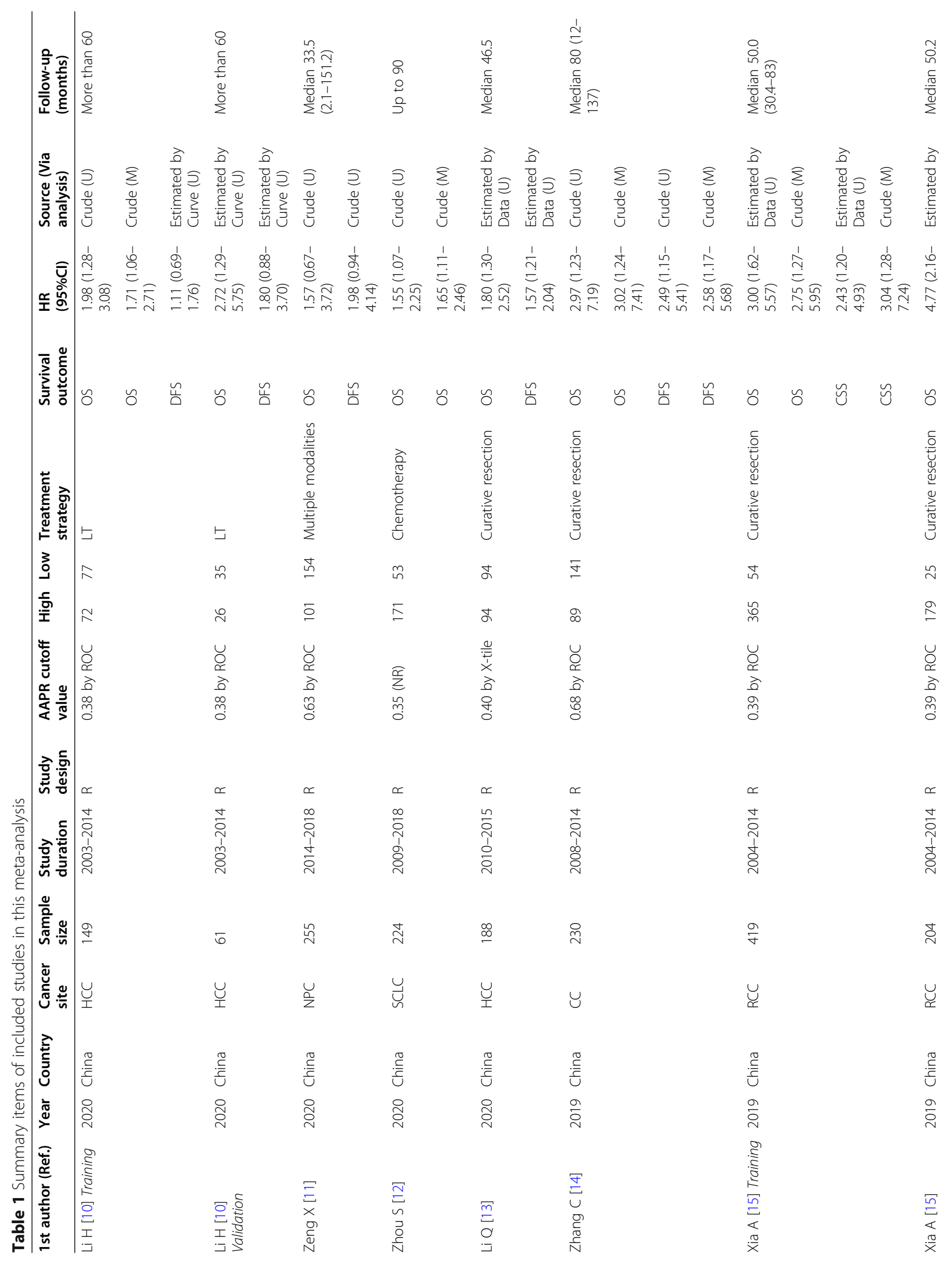


An et al. BMC Cancer $\quad$ (2021) 21:247

Page 6 of 18

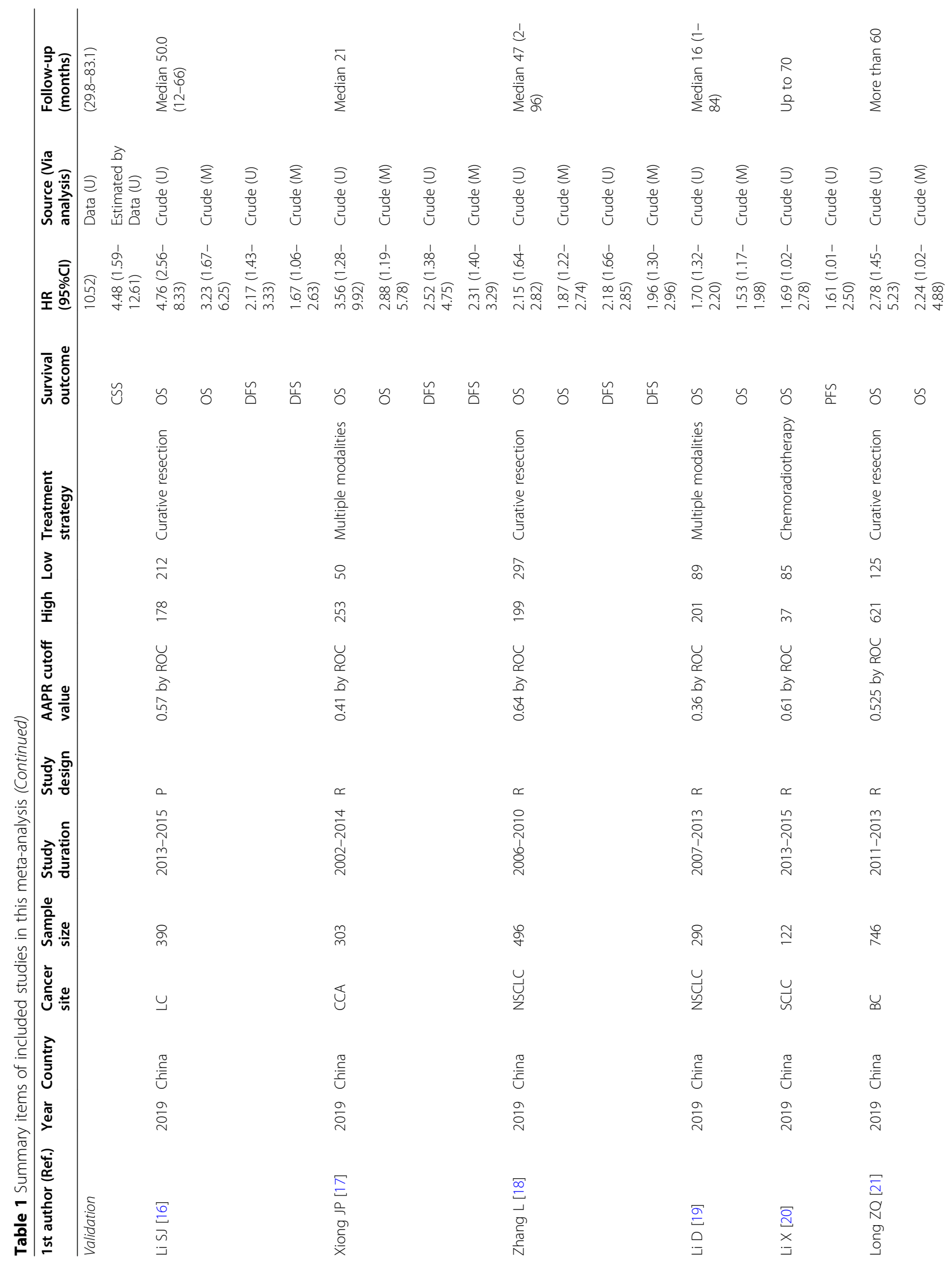


An et al. BMC Cancer $\quad$ (2021) 21:247

Page 7 of 18

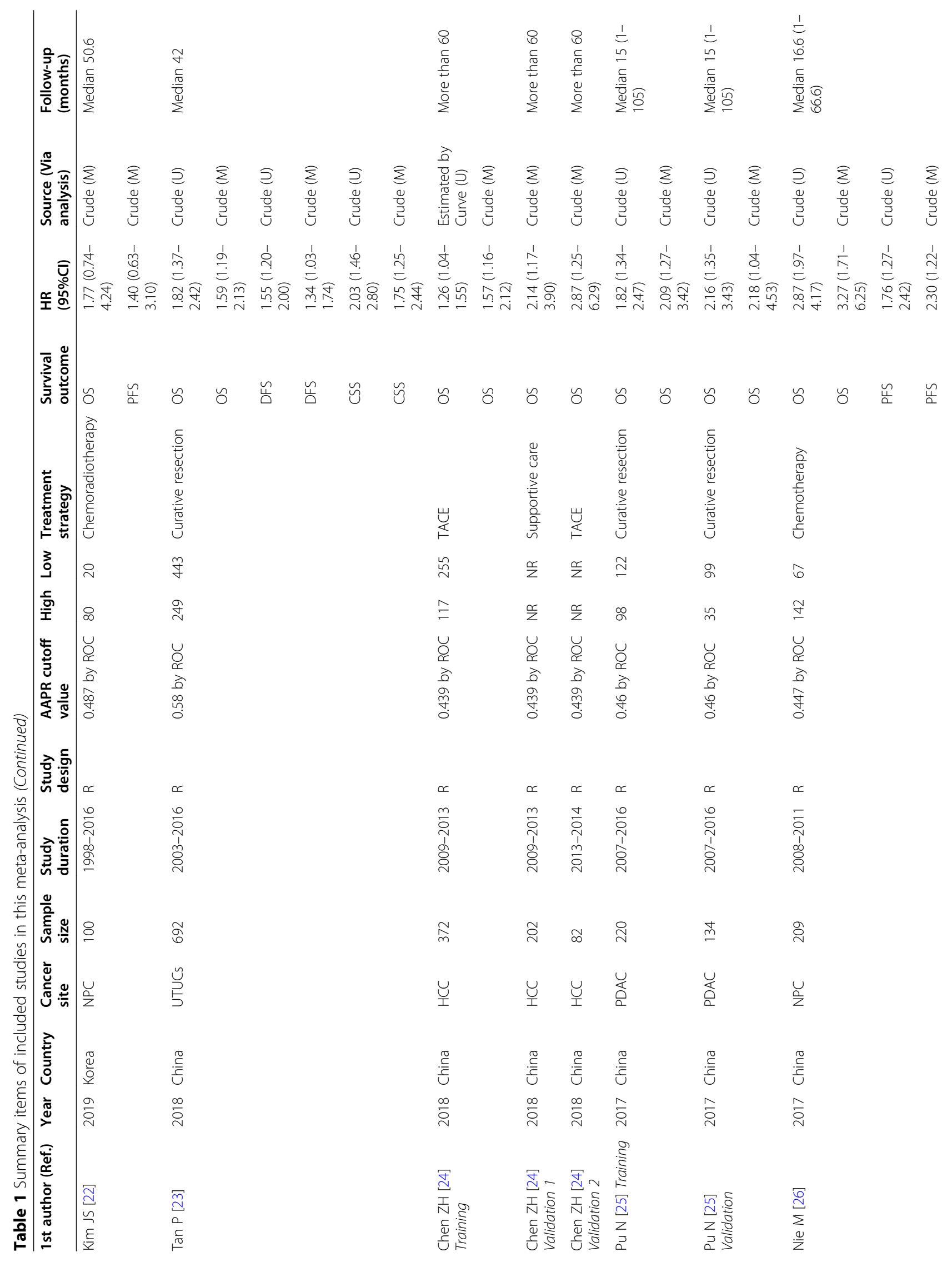




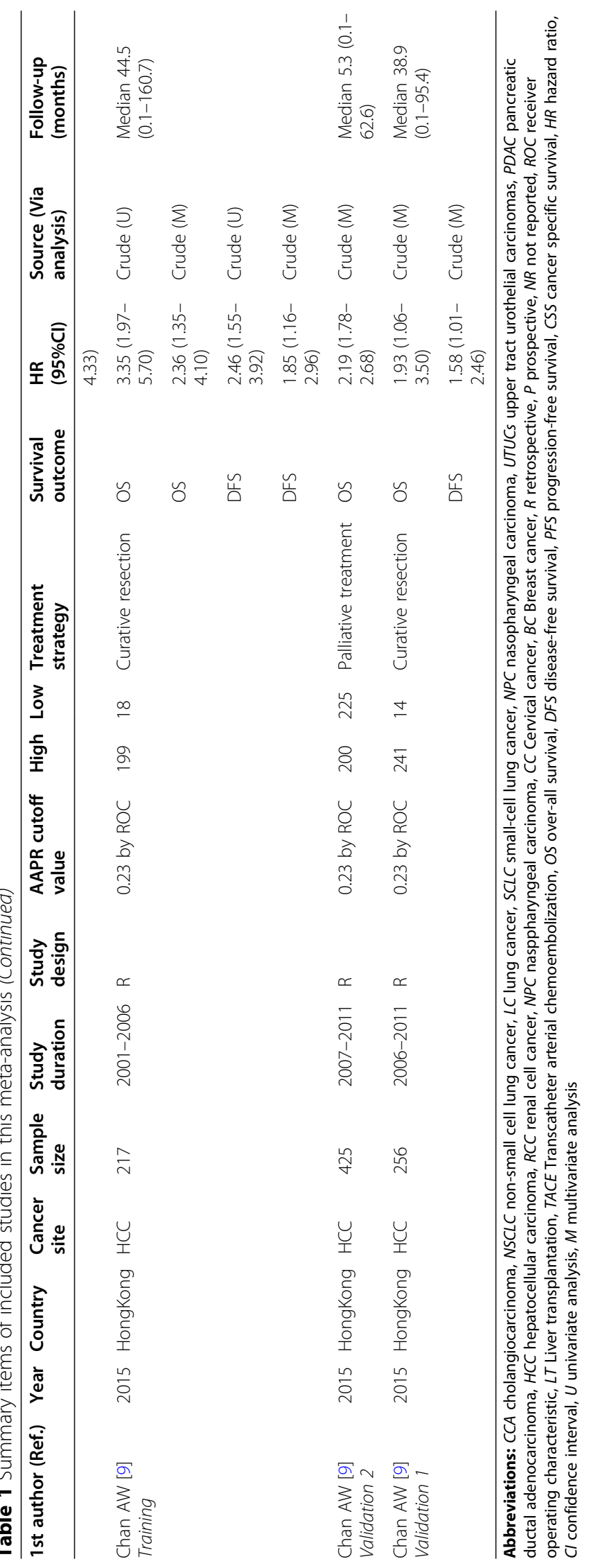




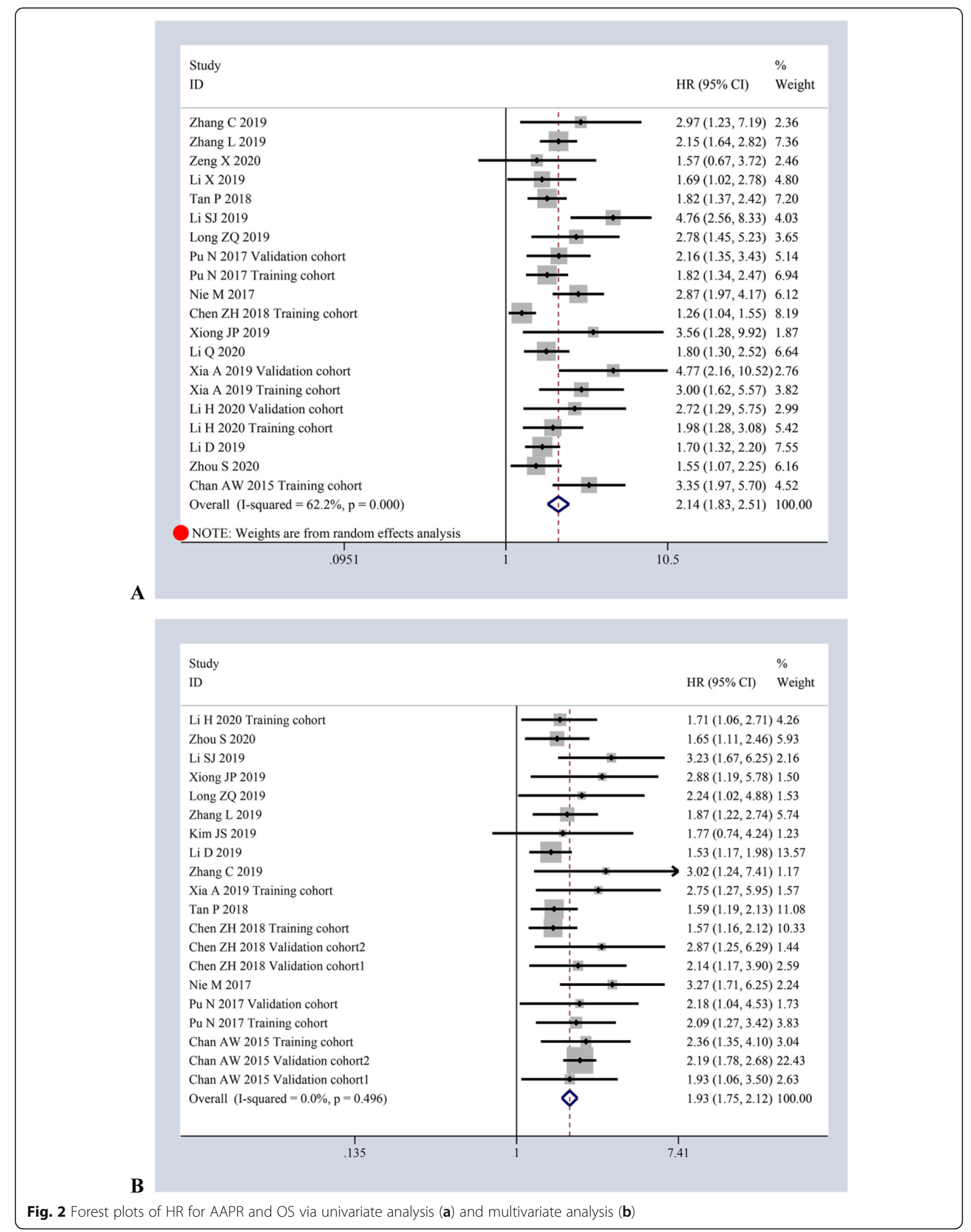


Study

ID

HR $(95 \% \mathrm{CI}) \quad$ Weight

Zeng X 2020

Li H 2020 Validation cohort

Li Q 2020

Li H 2020 Training cohort

Xiong JP 2019

Zhang L 2019

Li SJ 2019

Zhang C 2019

Tan P 2018

Chan AW 2015 Training cohort

Overall $(\mathrm{I}-$ squared $=29.5 \%, \mathrm{p}=0.174)$

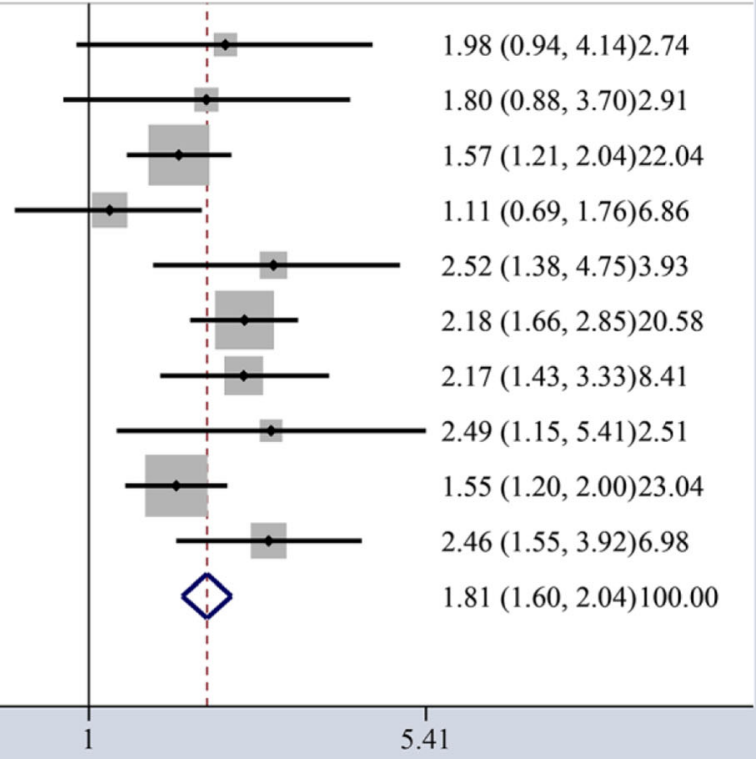

A

.185

5.41

Study

$\%$

ID

HR $(95 \% \mathrm{CI}) \quad$ Weight

Xiong JP 2019

Zhang L 2019

Chan AW 2015 Training cohort

Li SJ 2019

Tan P 2018

Zhang C 2019

Chan AW 2015 Validation cohort1

Overall (I-squared $=13.0 \%, \mathrm{p}=0.330)$

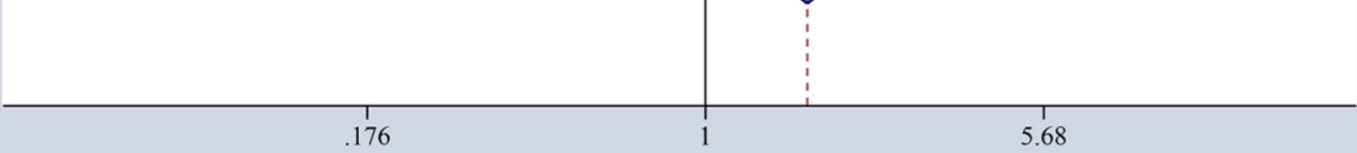

B

Fig. 3 Forest plots of HR for AAPR and DFS via univariate analysis (a) and multivariate analysis (b) 
Study

ID

HR (95\% CI) Weight

Univariate analysis

Nie M 2017

Li X 2019

Subtotal (I-squared $=0.0 \%, \mathrm{p}=0.754)$

Multivariate analysis

Nie M 2017

Kim JS 2019

Subtotal (I-squared $=0.0 \%, \mathrm{p}=0.339$ )

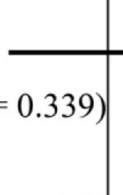

Heterogeneity between groups: $\mathrm{p}=0.713$

Overall (I-squared $=0.0 \%, p=0.766$ )

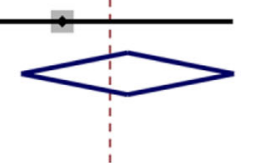

$1.76(1.27,2.42) 51.84$

$1.61(1.01,2.50) 26.24$

$1.71(1.31,2.22) 78.08$

O

.231

1

4.33

$2.30(1.22,4.33) 13.43$

$1.40(0.63,3.10) 8.49$

$1.90(1.16,3.12) 21.92$

A

Study

ID

HR $(95 \% \mathrm{CI})$

Weight

Univariate analysis

Xia A 2019 Validation cohort

Xia A 2019 Training cohort

Tan P 2018

Subtotal $($ I-squared $=5.6 \%, p=0.347)$

Multivariate analysis

Xia A 2019 Training cohort

Tan P 2018

Subtotal $(\mathrm{I}$-squared $=26.4 \%, \mathrm{p}=0.244)$

Heterogeneity between groups: $\mathrm{p}=0.442$

Overall $(\mathrm{I}$-squared $=1.7 \%, \mathrm{p}=0.397)$

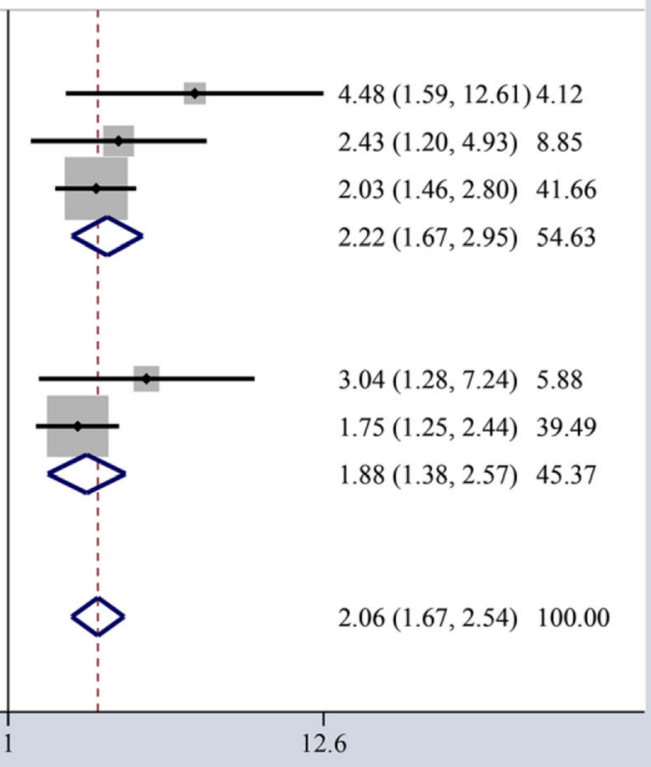

B

Fig. 4 Forest plots of HR for the impact of AAPR on PFS (a) and CSS (b) via both univariate and multivariate analytic analysis 
Table 2 Stratified analysis of OS meta-analysis results via univariate analysis

\begin{tabular}{|c|c|c|c|c|c|c|c|c|c|}
\hline \multirow{2}{*}{$\begin{array}{l}\text { Factor for } \\
\text { stratification }\end{array}$} & \multirow{2}{*}{$\begin{array}{l}\text { No. of } \\
\text { Cohorts }\end{array}$} & \multirow{2}{*}{$\begin{array}{l}\text { No. } \\
\text { of } \\
\text { Cases }\end{array}$} & \multirow{2}{*}{$\begin{array}{l}\text { No.of } \\
\text { Low } \\
\text { AAPR }\end{array}$} & \multirow{2}{*}{$\begin{array}{l}\text { N. of } \\
\text { High } \\
\text { AAPR }\end{array}$} & \multicolumn{3}{|c|}{ Pooled Data } & \multicolumn{2}{|c|}{ Test for Heterogeneity } \\
\hline & & & & & $\overline{H R}$ & $95 \% \mathrm{Cl}$ & $P$ value & $P^{2}(\%)$ & $P$ value \\
\hline Overall calculation & 20 & 5921 & 2495 & 3426 & 2.14 & $1.83-2.51$ & $<0.001$ & 62.2 & 0.000 \\
\hline \multicolumn{10}{|l|}{ Year of publication } \\
\hline After 2019 & 14 & 4077 & 1491 & 2586 & 2.20 & $1.85-2.63$ & $<0.001$ & 43.0 & 0.044 \\
\hline Before 2019 & 6 & 1844 & 1004 & 840 & 2.02 & $1.50-2.71$ & $<0.001$ & 78.9 & 0.000 \\
\hline \multicolumn{10}{|l|}{ Cancer site } \\
\hline Liver cancer & 5 & 997 & 479 & 508 & 1.96 & $1.37-2.80$ & $<0.001$ & 75.4 & 0.003 \\
\hline Lung cancer & 5 & 1522 & 736 & 786 & 2.03 & $1.52-2.70$ & $<0.001$ & 67.1 & 0.016 \\
\hline Others & 10 & 3412 & 1280 & 2312 & 2.32 & $1.92-2.80$ & $<0.001$ & 25.9 & 0.205 \\
\hline \multicolumn{10}{|l|}{ Sample size } \\
\hline$\geq 224$ & 11 & 4417 & 1873 & 2544 & 2.06 & $1.64-2.58$ & $<0.001$ & 69.2 & 0.000 \\
\hline$<224$ & 9 & 1504 & 622 & 882 & 2.24 & $1.86-2.71$ & $<0.001$ & 35.9 & 0.131 \\
\hline \multicolumn{10}{|c|}{ Cut-off value for $A A P R$} \\
\hline$\geq 0.487$ & 7 & 2931 & 1457 & 1474 & 2.25 & $1.75-2.88$ & $<0.001$ & 44.6 & 0.094 \\
\hline$<0.487$ & 13 & 2990 & 1038 & 1952 & 2.10 & $1.72-2.56$ & $<0.001$ & 67.0 & 0.000 \\
\hline \multicolumn{10}{|l|}{ Study design type } \\
\hline Prospective & 1 & 390 & 212 & 178 & 4.76 & $2.56-8.33$ & $<0.001$ & - & - \\
\hline Retrospective & 19 & 5531 & 2283 & 3248 & 2.05 & $1.77-2.37$ & $<0.001$ & 55.8 & 0.002 \\
\hline \multicolumn{10}{|l|}{ Treatment strategy } \\
\hline Resection & 11 & 3936 & 1630 & 2306 & 2.20 & $1.95-2.50$ & $<0.001$ & 47.9 & 0.038 \\
\hline Others & 9 & 1985 & 865 & 1120 & 1.64 & $1.46-1.86$ & $<0.001$ & 60.2 & 0.010 \\
\hline \multicolumn{10}{|l|}{ HR source } \\
\hline Crude & 16 & 5049 & 2287 & 2762 & 2.14 & $1.85-2.47$ & $<0.001$ & 40.4 & 0.053 \\
\hline Estimated & 4 & 872 & 208 & 664 & 2.21 & $1.42-3.44$ & $<0.001$ & 79.2 & 0.001 \\
\hline \multicolumn{10}{|l|}{ Follow-up interval } \\
\hline$\geq 5$ years & 11 & 3385 & 1171 & 2214 & 2.36 & $1.81-3.06$ & $<0.001$ & 70.1 & 0.000 \\
\hline$<5$ years & 9 & 2536 & 1324 & 1212 & 2.01 & $1.66-2.42$ & $<0.001$ & 51.8 & 0.035 \\
\hline
\end{tabular}

CSS in human cancers. In other words, decreased AAPR was associated with high mortality rate and high recurrence rate in cases with cancers.

In specific cases, both the univariate analytic results and the multivariate analytic results, were exploited and synthesized to evaluate the prognostic role of AAPR on OS/DFS/PFS/CSS. The combined meta-analysis results from these two analytic methods were unanimous. Heterogeneity is significant in OS via univariate analytic results, which might be due to the diverse clinicopathological factors, including patient's characteristics, tumor classification, tumor stage, as well as follow-up interval. A stratified analysis was further conducted according to possible factors. Heterogeneity still existed in some of the subgroups, but as previously stated, the interaction between AAPR and OS remained stable. Publication bias was identified in the metaanalysis with OS via univariate and multivariate analysis, and therefore, trim and fill method was also further exploited to testify the association between AAPR and OS. Similarly, the adjusted meta-analysis results also demonstrated that AAPR significantly correlated with poor OS. In general, these results suggested that our meta-analysis results were comprehensive and convincing.

Albumin, the most abundant protein in plasma, is synthesized and secreted from the liver, and its concentration reflects the protein status of the blood and function of internal organs [6]. Hypoalbuminemia is frequently observed in human malignancies, which often serves as an indicator of poor nutritional status and also correlates with poor outcomes of cancer patients [6, 34]. Additionally, albumin has the physiological properties as an antioxidant and drug transporter, and therefore, hypoalbuminemia could cause the insufficiency of these functions, leading to poor postoperative outcomes [35]. Moreover, 
Filled funnel plot with pseudo $95 \%$ confidence limits

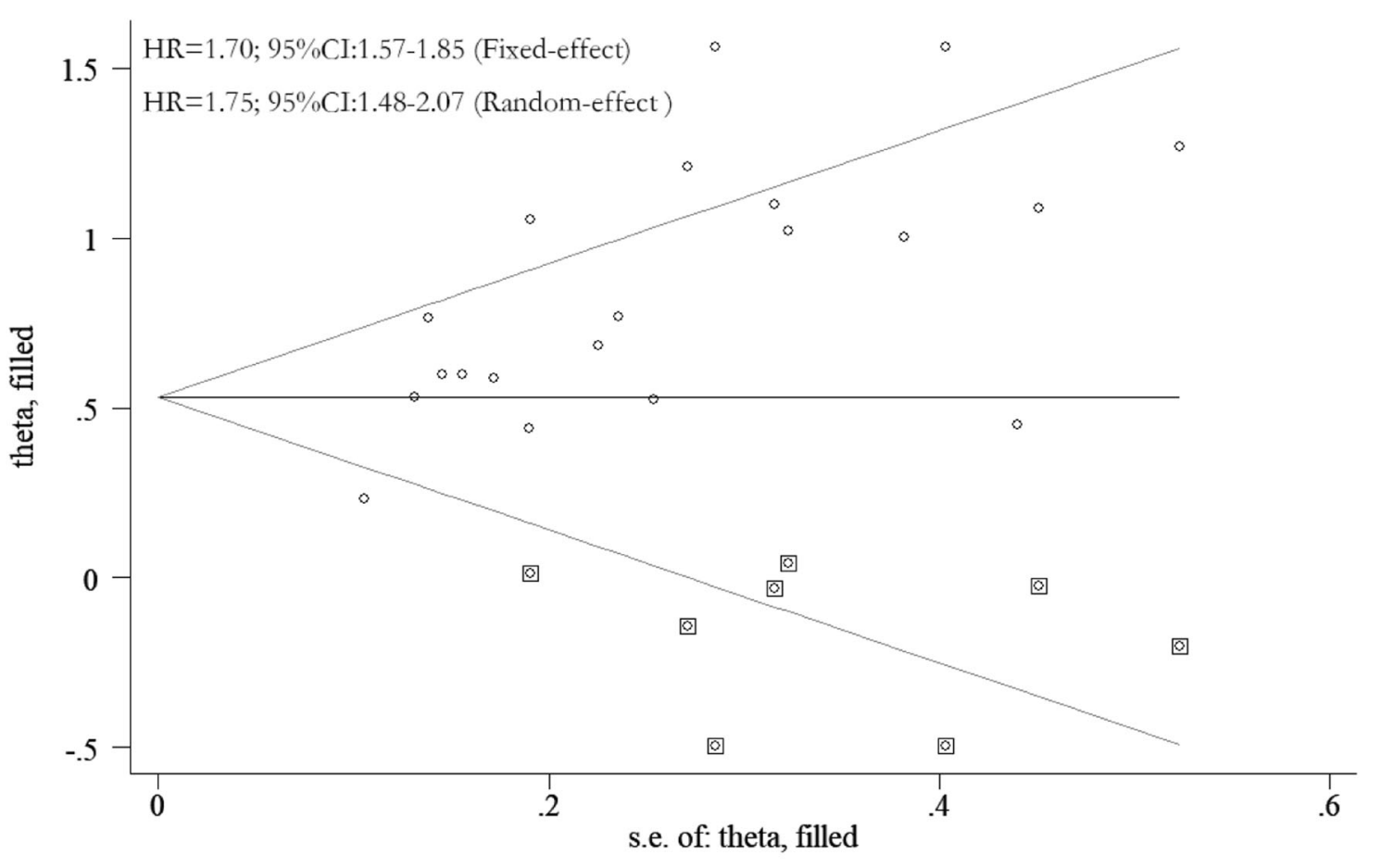

A

Filled funnel plot with pseudo $95 \%$ confidence limits

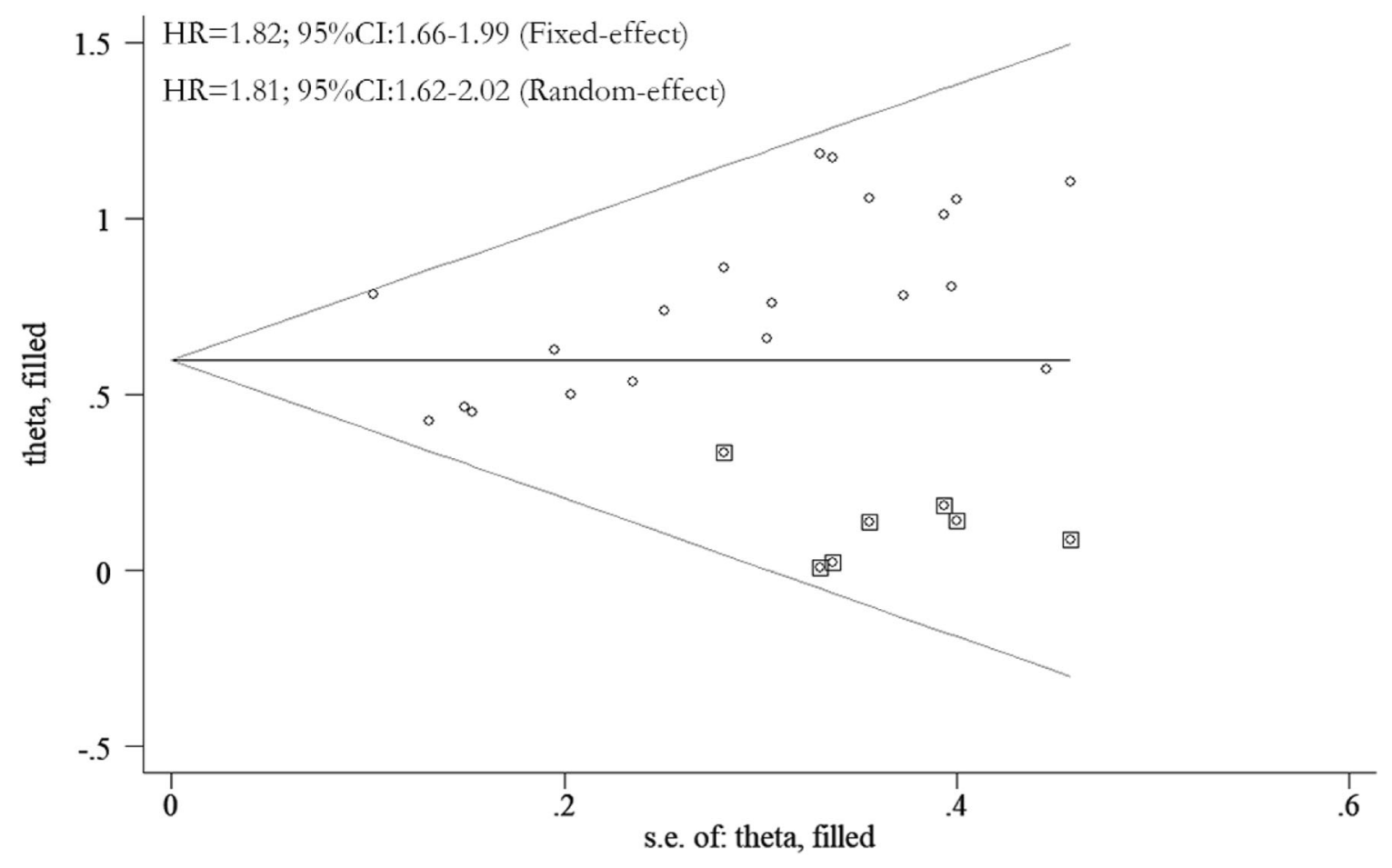

B

Fig. 5 Adjusted meta-analysis results for OS via univariate analysis (a) and multivaritate analysis (b) by following the trim and fill method 

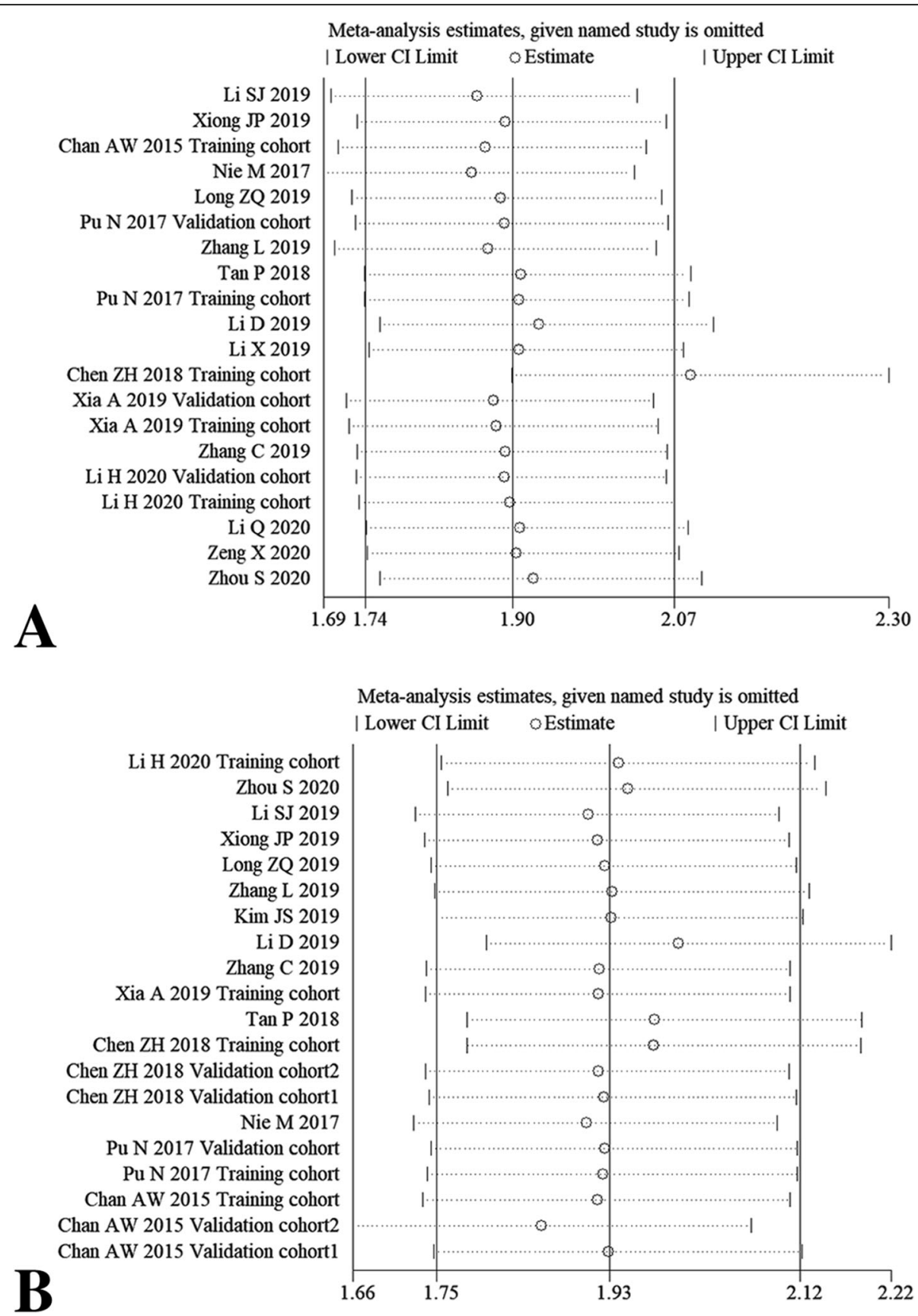

Fig. 6 Sensitivity analysis for OS via univariate analytic results (a) and multivariate analytic results (b), DFS via univariate analytic results (c) and multivariate analytic results (d), PFS (e) and CSS (f) by omitting single included study

as a negative acute phase protein, albumin is associated with increased inflammatory status, whereupon increased inflammation usually leads to poor outcomes [35].

ALP comprising a heterogeneous group of enzymes, which are expressed and distributed in different human body tissues [36]. Accordingly, ALP can be categorized into tissue-specific and tissue nonspecific types. The tissue-specific type of ALP is only found in the intestine, placenta, and germinal tissue, whereas it can also secrete into circulation under specific stimulation. In contrast, the tissue-nonspecific ALP in the circulation (secreted by liver, bone, and kidneys) is gaining the interest of clinicians [36]. Use of ALP as a tumor marker can be dated back to the 1980s [37]. From then on, hyperphosphatasia (Namely, elevated ALP level) has been proposed as prognostic indicator in various cancers, including prostate cancer [38], renal cell carcinoma [39], HCC [40], gastric cancer [41], pancreatic cancer [42], and osteosarcoma 


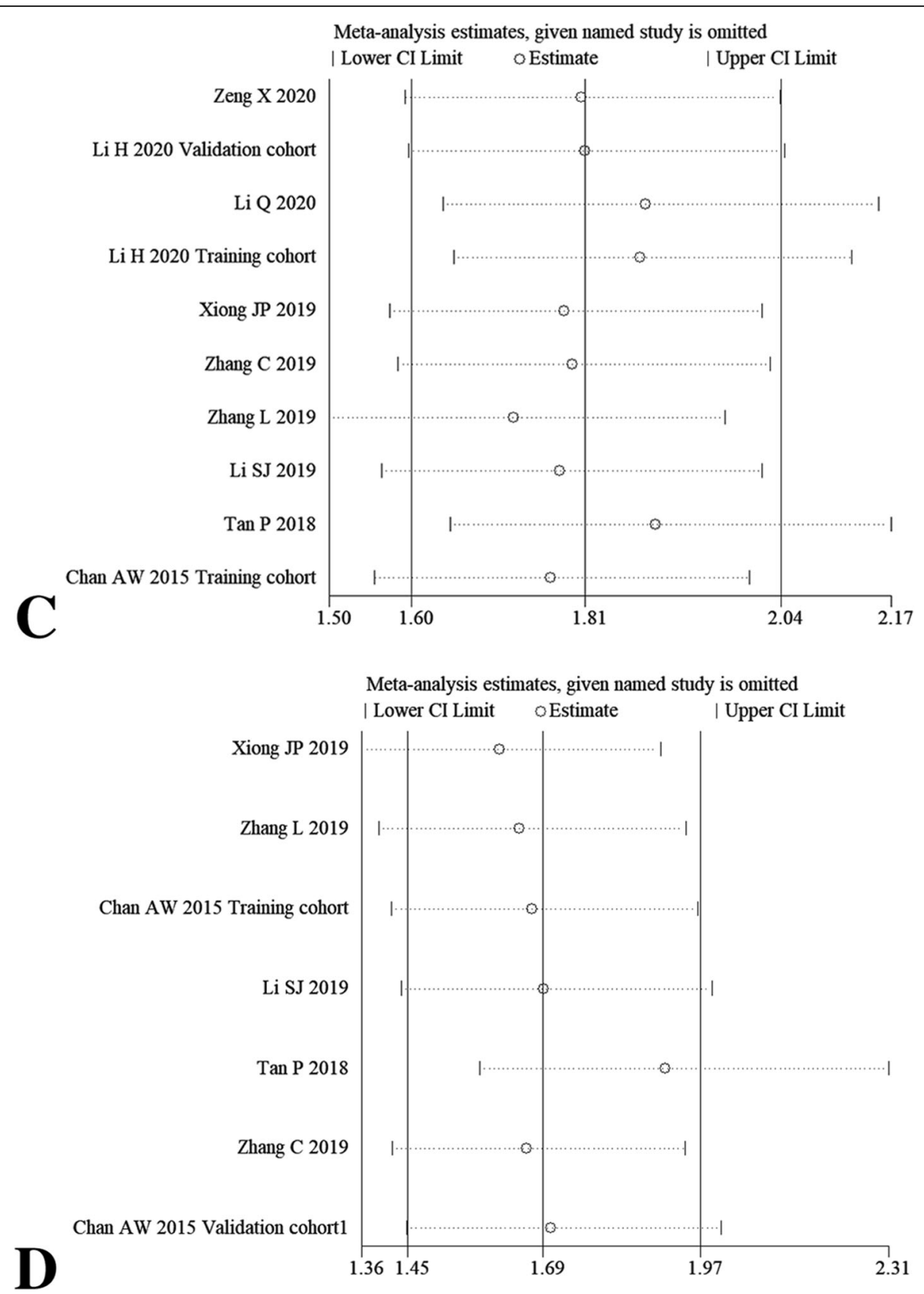

Fig. 6 Sensitivity analysis for OS via univariate analytic results (a) and multivariate analytic results (b), DFS via univariate analytic results (c) and multivariate analytic results (d), PFS (e) and CSS (f) by omitting single included study

[43]. It has been previously proven that hyperphosphatasia is present in primary or metastatic cancer via increasing liver isoenzyme leakage, as well as causing local biliary obstruction [44]. Nevertheless, primary extrahepatic cancer does not necessarily have to involve the liver or bone, because some cancers present with paraneoplastic effect, resulting in liver isoenzyme leakage into serum (eg. renal cell carcinoma), and some rare cancers can also produce ALP (eg. Hodgkin lymphoma) [44].
The underlining mechanism behind AAPR becoming a prognostic indicator of human cancers should be due to the pathological properties of hypoalbuminemia and hyperphosphatasia. Indeed, the decrease of AAPR could be caused by either one or both of the two abnormalities, both of which significantly correlate with poor outcomes in human cancers. When compared with single indicator-hypoalbuminemia or hyperphosphatasia, AAPR might contribute to identifying more patients with poor prognosis, because some cases might present 

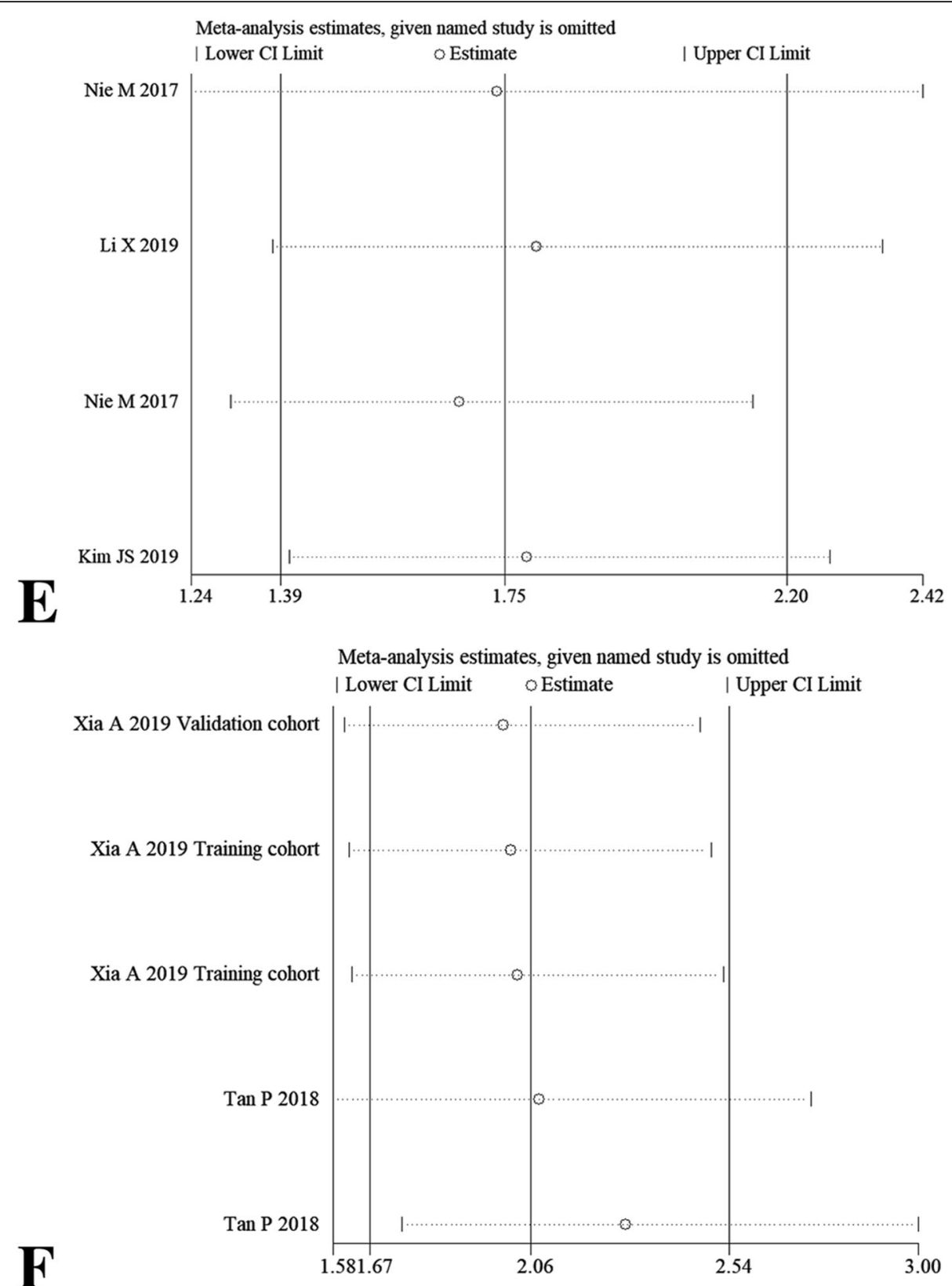

Fig. 6 Sensitivity analysis for OS via univariate analytic results (a) and multivariate analytic results (b), DFS via univariate analytic results (c) and multivariate analytic results (d), PFS (e) and CSS (f) by omitting single included study

with normal serum albumin levels but hyperphosphatasia, or normal serum ALP levels but hypoalbuminemia. It's well-known that both albumin and ALP are common serum biochemical indicators used during clinical work. Therefore, we inferred that AAPR can serve as a more practical and more comprehensive indicator of prognosis in human cancers. However, our meta-analysis results were based on available researches from Asian countries, the prognostic role of AAPR in cancers also needs to be assessed by further research in western countries, especially research conducted in the greater cancer community. Additionally, well-designed clinical diagnostic research based on large scale (comparing the accuracy of $A A P R, A L B$, and $A L P$ ), or meta-analysis based on diagnostic research is still warranted to clarify this issue.

Importantly, it should be noted that neither hypoalbuminemia nor hyperphosphatasia is cancer-specific. For instance, hypoalbuminemia could also be caused by malnutrition, as well as diverse benign diseases, such as liver disease, infectious disease, and nephrotic syndrome [45, 46]. Meanwhile, hyperphosphatasia is also involved in a variety of pathological processes not exclusive to cancer. 
This includes liver dysfunction (eg. bile duct obstruction), bone diseases (eg. bone formation after fracture) and endocrine diseases (eg. hyperparathyroid) [36]. Therefore, attention should be paid to these potential confounding factors when exploiting AAPR as potential prognostic marker in patients with cancers.

\section{Conclusions}

In summary, decreased AAPR had adverse effects on prognosis in patients with cancers. As an inexpensive and convenient ratio derived from LFT, AAPR might become a promising indicator of prognosis in human cancers.

\section{Supplementary Information}

The online version contains supplementary material available at https://doi. org/10.1186/s12885-021-07921-6.

Additional file 1: Supplementary table. The Newcastle-Ottawa Scale (NOS) scores for incorporated studies of this meta-analysis.

\section{Abbreviations}

AAPR: Albumin-to-alkaline phosphatase ratio; HR: Hazard ratio; Cl: Confidence interval; OS: Overall survival; DFS: Disease-free survival; PFS: Progression-free survival; CSS: Cancer-specific survival

\section{Acknowledgments}

Herein, we thanked the authors of the 18 included studies (used in this meta-analysis). Based on their previously published work, we performed this present meta-analysis. Additionally, we appreciate the reviewers who selflessly reviewed this manuscript, as well as the the journal staffs who responsibly worked for our manuscript.

\section{Authors' contributions}

AL, YWT, and SDW designed this research. AL and SDW did data analysis and wrote this paper. All of the three authors have read and approved of the final version of manuscript.

\section{Funding}

This research was supported by Department of Science and Technology of Jilin Province (No. 20200603001SF).

\section{Availability of data and materials}

Nearly all the data $(\mathrm{HR}$ with $95 \% \mathrm{Cl})$ used in this meta-analysis were directly extracted from the 18 included studies originally, except 4 studies in which HR associated results were estimated according to Kaplan-Meier Curve or survival data.

\section{Ethics approval and consent to participate}

For this type of study ethics approval and consent to participate are not needed.

\section{Consent for publication}

For this type of study formal consent for publication is not needed.

\section{Competing interests}

We declare that there is no competing interests in this research.

\section{Author details}

${ }^{1}$ Department of Hand Surgery, China-Japan Union Hospital of Jilin University, Changchun 130033, Jilin, China. ${ }^{2}$ Department of Hepatobiliary and Pancreatic Surgery, The First Hospital of Jilin University, Changchun 130021, Jilin, China.
Received: 25 June 2020 Accepted: 16 February 2021

Published online: 08 March 2021

\section{References}

1. Siegel RL, Miller KD, Jemal A. Cancer statistics, 2019. CA Cancer J Clin. 2019; 69:7-34.

2. Bray F, Ferlay J, Soerjomataram I, et al. Global cancer statistics 2018: GLOBOCAN estimates of incidence and mortality worldwide for 36 cancers in 185 countries. CA Cancer J Clin. 2018:68:394-424.

3. Miller KD, Nogueira L, Mariotto $A B$, et al. Cancer treatment and survivorship statistics, 2019. CA Cancer J Clin. 2019:69:363-85.

4. Ekser B, Veroux M. New prognostic indicators in surgery. Int J Surg. 2019;68: 176-7.

5. Hülshoff A, Schricker T, Elgendy $H$, et al. Albumin synthesis in surgical patients. Nutrition. 2013:29:703-7.

6. Fanali G, di Masi A, Trezza $V$, et al. Human serum albumin: from bench to bedside. Mol Asp Med. 2012;33:209-90.

7. Siller AF, Whyte MP. Alkaline phosphatase: discovery and naming of our favorite enzyme. J Bone Miner Res. 2018;33:362-4.

8. Zaher DM, El-Gamal MI, Omar HA, et al. Recent advances with alkaline phosphatase isoenzymes and their inhibitors. Arch Pharm (Weinheim). 2020; 353:e2000011.

9. Chan AW, Chan SL, Mo FK, et al. Albumin-to-alkaline phosphatase ratio: a novel prognostic index for hepatocellular carcinoma. Dis Markers. 2015;2015: 564057. https://doi.org/10.1155/2015/564057. Epub 2015 Feb 9. PMID: 25737613: PMCID: PMC4337043.

10. Li H, Wang L, Chen LZ, et al. Prognostic value of albumin-to-alkaline phosphatase ratio in hepatocellular carcinoma patients treated with liver transplantation. J Cancer. 2020;11:2171-80.

11. Zeng X, Liu G, Pan Y, et al. Prognostic value of clinical biochemistry-based indexes in nasopharyngeal carcinoma. Front Oncol. 2020;10:146.

12. Zhou S, Wang H, Jiang W, et al. Prognostic value of pretreatment albuminto-alkaline phosphatase ratio in extensive-disease small-cell lung Cancer: a retrospective cohort study. Cancer Manag Res. 2020;12:2015-24.

13. Li Q, Lyu Z, Wang L, et al. Albumin-to-alkaline phosphatase ratio associates with good prognosis of hepatitis B virus-positive HCC patients. Onco Targets Ther. 2020;13:2377-84.

14. Zhang C, Li Y, Ji R, et al. The prognostic significance of pretreatment albumin/alkaline phosphatase ratio in patients with stage IB-IIA cervical Cancer. Onco Targets Ther. 2019;12:9559-68.

15. Xia A, Chen Y, Chen J, et al. Prognostic value of the albumin-to-alkaline phosphatase ratio on urologic outcomes in patients with non-metastatic renal cell carcinoma following curative nephrectomy. J Cancer. 2019;10: 5494-503.

16. Li SJ, Lv WY, Du H, et al. Albumin-to-alkaline phosphatase ratio as a novel prognostic indicator for patients undergoing minimally invasive lung cancer surgery: propensity score matching analysis using a prospective database. Int J Surg. 2019:69:32-42

17. Xiong JP, Long JY, Xu WY, et al. Albumin-to-alkaline phosphatase ratio: a novel prognostic index of overall survival in cholangiocarcinoma patients after surgery. World J Gastrointest Oncol. 2019;11:39-47.

18. Zhang $L$, Zhang $H$, Yue D, et al. The prognostic value of the preoperative albumin to alkaline phosphatase ratio in patients with non-small cell lung cancer after surgery. Thorac Cancer. 2019;10:1581-9.

19. Li D, Yu H, Li W. Albumin-to-alkaline phosphatase ratio at diagnosis predicts survival in patients with metastatic non-small-cell lung cancer. Onco Targets Ther. 2019;12:5241-9.

20. Li X, Li B, Zeng H, et al. Prognostic value of dynamic albumin-to-alkaline phosphatase ratio in limited stage small-cell lung cancer. Future Oncol. 2019;15:995-1006

21. Long ZQ, Hua X, Zhang WW, et al. Prognostic impact of the pretreatment albumin to alkaline phosphatase ratio for nonmetastatic breast cancer patients. Cancer Manag Res. 2019;11:4809-14.

22. Kim JS, Keam B, Heo DS, et al. The prognostic value of albumin-to-alkaline phosphatase ratio before radical radiotherapy in patients with nonmetastatic nasopharyngeal carcinoma: a propensity score matching analysis. Cancer Res Treat. 2019;51:1313-23.

23. Tan $\mathrm{P}, \mathrm{Xie} \mathrm{N}, \mathrm{Ai}$ J, et al. The prognostic significance of albumin-to-alkaline phosphatase ratio in upper tract urothelial carcinoma. Sci Rep. 2018;8:12311.

24. Chen ZH, Zhang XP, Cai XR et al. The predictive value of albumin-toalkaline phosphatase ratio for overall survival of hepatocellular carcinoma 
patients treated with trans-catheter arterial chemoembolization therapy. J Cancer. 2018;9:3467-78.

25. Pu N, Gao S, Xu Y, et al. Alkaline phosphatase-to-albumin ratio as a prognostic Indicator in pancreatic ductal adenocarcinoma after curative resection. J Cancer. 2017;8:3362-70.

26. Nie M, Sun P, Chen C, et al. Albumin-to-alkaline phosphatase ratio: a novel prognostic index of overall survival in Cisplatin-based chemotherapy-treated patients with metastatic nasopharyngeal carcinoma. J Cancer. 2017;8:80915.

27. Moher D, Liberati A, Tetzlaff J, et al. Preferred reporting items for systematic reviews and meta-analyses: the PRISMA statement. PLoS Med. 2009;6: e1000097.

28. Tierney JF, Stewart LA, Ghersi D, et al. Practical methods for incorporating summary time-to-event data into meta-analysis. Trials. 2007;8:16.

29. Altman DG. Systematic reviews of evaluations of prognostic variables. BMJ. 2001;323:224-8.

30. Begg CB, Mazumdar M. Operating characteristics of a rank correlation test for publication bias. Biometrics. 1994;50:1088-101.

31. Egger M, Davey Smith G, Schneider M, Minder C. Bias in meta-analysis detected by a simple, graphical test. BMJ. 1997;315:629-34.

32. Duval S, Tweedie R. Trim and fill: a simple funnel-plot-based method of testing and adjusting for publication bias in meta-analysis. Biometrics. 2000; 56:455-63.

33. Lv GY, An L, Sun XD, et al. Pretreatment albumin to globulin ratio can serve as a prognostic marker in human cancers: a meta-analysis. Clin Chim Acta. 2018:476:81-91.

34. Loftus TJ, Brown MP, Slish JH, et al. Serum levels of Prealbumin and albumin for preoperative risk stratification. Nutr Clin Pract. 2019;34:340-8.

35. Kim S, McClave SA, Martindale RG, et al. Hypoalbuminemia and clinical outcomes: what is the mechanism behind the relationship? Am Surg. 2017; 83:1220-7.

36. Sharma U, Pal D, Prasad R. Alkaline phosphatase: an overview. Indian J Clin Biochem. 2014;29:269-78.

37. Higashino K, Otani R. Alkaline phosphatase as a tumor marker. Nihon Rinsho. 1980;38:4588-98.

38. Høisaeter PA. Alkaline phosphatase. A marker in prostatic cancer? Acta Oncol. 1991:30:171-2.

39. Chuang YC, Lin AT, Chen KK, et al. Paraneoplastic elevation of serum alkaline phosphatase in renal cell carcinoma: incidence and implication on prognosis. J Urol. 1997;158:1684-7.

40. Yu MC, Chan KM, Lee CF, et al. Alkaline phosphatase: does it have a role in predicting hepatocellular carcinoma recurrence? I Gastrointest Surg. 2011; 15:1440-9.

41. Namikawa T, Ishida N, Tsuda S, et al. Prognostic significance of serum alkaline phosphatase and lactate dehydrogenase levels in patients with unresectable advanced gastric cancer. Gastric Cancer. 2019;22:684-91.

42. Xiao Y, Lu J, Chang W, et al. Dynamic serum alkaline phosphatase is an indicator of overall survival in pancreatic cancer. BMC Cancer. 2019:19:785.

43. Hao H, Chen L, Huang D, et al. Meta-analysis of alkaline phosphatase and prognosis for osteosarcoma. Eur J Cancer Care. 2017:26:10.

44. Lowe D, John S. Alkaline phosphatase. In: StatPearls [internet]. StatPearls: Treasure Island (FL); 2020. PMID: 29083622

45. Soeters PB, Wolfe RR, Shenkin A. Hypoalbuminemia: pathogenesis and clinical significance. JPEN J Parenter Enteral Nutr. 2019;43:181-93.

46. Gatta A, Verardo A, Bolognesi M. Hypoalbuminemia. Intern Emerg Med. 2012;Suppl 3:S193-9. https://doi.org/10.1007/s11739-012-0802-0. PMID: 23073857.

\section{Publisher's Note}

Springer Nature remains neutral with regard to jurisdictional claims in published maps and institutional affiliations.

Ready to submit your research? Choose BMC and benefit from:

- fast, convenient online submission

- thorough peer review by experienced researchers in your field

- rapid publication on acceptance

- support for research data, including large and complex data types

- gold Open Access which fosters wider collaboration and increased citations

- maximum visibility for your research: over $100 \mathrm{M}$ website views per year

At $\mathrm{BMC}$, research is always in progress.

Learn more biomedcentral.com/submissions 